\title{
Gender disparities in treatment response in octogenarians with acute coronary syndrome
}

\author{
Pablo Díez-Villanueva ${ }^{1}$, Lourdes Vicent ${ }^{2}$, Fernando Alfonso $^{1}$ \\ ${ }^{1}$ Department of Cardiology, La Princesa University Hospital, Autonoma University of Madrid, Madrid, Spain; ${ }^{2}$ Department of Cardiology, Doce de \\ Octubre University Hospital, Madrid, Spain \\ Correspondence to: Pablo Díez-Villanueva, MD, PhD. Department of Cardiology, La Princesa University Hospital, Health Research Institute, IIS-IP. \\ CIVER-CV. Autonoma University of Madrid, c/ Diego de León 62, Madrid 28006, Spain. Email: pablo_diez_villanueva@hotmail.com. \\ Provenance and Peer Review: This article was commissioned by the Editorial Office, Fournal of Thoracic Disease. The article did not undergo external peer review. \\ Comment on: Sui YG, Teng SY, Qian J, et al. Gender differences in treatment strategies among patients $\geq 80$ years old with non-ST-segment elevation \\ myocardial infarction. J Thorac Dis 2019;11:5258-65.
}

Submitted Jan 27, 2020. Accepted for publication Feb 20, 2020.

doi: $10.21037 /$ jtd.2020.03.41

View this article at: http://dx.doi.org/10.21037/jtd.2020.03.41

Coronary artery disease is one of the leading causes of death and morbidity worldwide (1). In addition to classic cardiovascular risk factors, age is the strongest risk factor of coronary artery disease, as well as an independent predictor of poor outcomes following an acute coronary syndrome (2). In the last decades we are witnessing a notable rise in life expectancy. Thanks to healthcare improvements, many diseases have become chronic processes, so the rise in life expectancy has been accompanied by a parallel increase in patients' comorbidities $(3,4)$, which imposes a challenge in their treatment.

Non-ST segment elevation acute coronary syndrome (NST-ACS) is the most common presentation of acute myocardial infarction (approximately 3 out of 4 patients), especially in the elderly $(2,5)$. Near $40 \%$ of patients presenting a NST-ACS are $\geq 75$-year-old (2). Despite this high prevalence, older patients are underrepresented in clinical trials addressing the efficacy of acute coronary syndrome therapies $(6,7)$, so there is great uncertainty regarding the best treatment options in this scenario. Moreover, polypharmacy, which is common in the elderly, predisposes to adverse effects and pharmacological interactions, so usual medications may have a detrimental impact on comorbidities (such as statins on myopathy, or beta-blockers aggravating obstructive lung disease) (8). Regarding coronary angiography, which is the preferred strategy in patients presenting an acute coronary syndrome (9), there are few studies addressing the potential benefit of an invasive approach in octogenarians presenting a NST-ACS (10), as this is a heterogeneous group.

In this issue of the Journal, Sui et al. (11) report gender impact on treatment effectiveness and survival in very elderly patients admitted due to an NST-ACS. This is an interesting but retrospective analysis of consecutive patients with NST-ACS from a single center in China. Baseline characteristics, comorbidities and relevant conditions were collected and compared among patients who underwent invasive and conservative strategies in men and women. However, a detailed direct comparison of baseline characteristics and clinical outcomes between men and women with NST-ACS was not performed. Overall, the invasive treatment was associated with a reduction in mortality in both genders. However, after adjusting for potential confounders the invasive strategy was only associated with a better survival in men, but not in women. Interestingly the survival curves keep diverging beyond the second year in men further suggesting the long-term benefit of revascularization in this cohort. Although these findings would suggest that an invasive strategy is less likely to confer a clinical benefit in women, some important methodological issues should be considered. First, the sample size was very limited (and the proportion of women was markedly low, near one third) and this seriously limits the robustness of the findings. This is of special concern considering the multiple subgroups analyses and also the endpoint of mortality selected. The study is largely unpowered in this regard. 
Second, many unmeasured confounders may have played a major role in the differences between genders. As women tend to have more adverse baseline clinical and anatomic characteristics it is also likely that other important adverse characteristics and comorbidities would be more frequent in women yet would have been overlooked due to the retrospective nature of the study. This gender gap has also been reported in previous studies (12-15), associating lower invasive treatment including coronary angiography and revascularization, antiplatelet drugs, and other secondary prevention medications in women (16). These two concerns, namely small sample size and the retrospective and observational design suggest that the study findings should be considered at most as hypothesis generating. However, some randomized and real-life studies have showed that revascularization is clearly beneficial in elderly women, with a reduction in 1-year mortality, and without a significant increase in adverse effects (especially major bleeding) (15). After adjusting for age and comorbidities, women tend to have an improved survival compared with men $(12,14)$.

Furthermore, previous studies have consistently demonstrated that women had more adverse anatomic features for percutaneous coronary interventions. However, lesions characteristics, and particularly vessel size, were not evaluated in the current study. Moreover, whether a similar rate of complete revascularization was achieved in both groups remains unclear. Additionally, bleeding complications are classically more frequent in women and in elderly patients in general but, unfortunately, this important information was not collected in this study. Apparently, new potent platelet inhibitors were not used in this study. The potential influence of dual antiplatelet therapy (DAPT) and a radial access in this regard merit further investigation in octogenarians presenting with NST-ACS.

On the other hand, in recent years, frailty has emerged as a concept of great value to guide treatment, and clarify the prognosis in elderly patients (17). Frailty, defined as a state of vulnerability with reduced capacity to respond and adapt to external stressors $(18,19)$, is very common in elderly patients (18). Frailty and acute coronary syndrome often coexist $(19,20)$, entailing higher mortality and less use of invasive treatment, and subsequent coronary revascularization (20,21). Frailty assessment should be mandatory in patients presenting a NST-ACS, as it is a powerful predictor of poor outcomes, with higher mortality and readmissions (22), though there is uncertainty about the most appropriate management regarding invasive coronary intervention in frail elderly patients (23). However, it is not routinely measured in daily clinical practice (19), and was not taken into account in the work of Sui et al. (11). It is uncertain whether the differences in treatment response by sex are explained by biological factors and gender particularities per se, or inequity in the administration of therapies and patients' selection. We could assume that the minor benefit derived from the invasive treatment observed in the group of elderly women with NST-ACS (11) could be attributed, at least in part, to a higher prevalence of frailty in this group, compared to men.

Finally, with respect to the definition of endpoints of studies focused in elderly patients, mortality alone may not be appropriate, as the impact of a specific therapy or intervention on survival may be low. Quality of lifebased endpoints, hospital readmissions, complications, and dependence in the medium-term may be more appropriate.

More studies are eagerly needed to establish the value of an invasive strategy in elderly women with NST-ACS. In the meantime, the potential benefit of an invasive strategy should be offered to elder women presenting with NSTACS after a careful holistic (cardiac and geriatric) clinical evaluation of the individualized risk-benefit balance.

\section{Acknowledgments}

Funding: None.

\section{Footnote}

Conflicts of Interest: All authors have completed the ICMJE uniform disclosure form (available at http://dx.doi. org/10.21037/jtd.2020.03.41). The authors have no conflicts of interest to declare.

Ethical Statement: The authors are accountable for all aspects of the work in ensuring that questions related to the accuracy or integrity of any part of the work are appropriately investigated and resolved.

Open Access Statement: This is an Open Access article distributed in accordance with the Creative Commons Attribution-NonCommercial-NoDerivs 4.0 International License (CC BY-NC-ND 4.0), which permits the noncommercial replication and distribution of the article with the strict proviso that no changes or edits are made and the original work is properly cited (including links to both the formal publication through the relevant DOI and the license). See: https://creativecommons.org/licenses/by-nc-nd/4.0/. 


\section{References}

1. Asaria P, Elliott P, Douglass M, et al. Acute myocardial infarction hospital admissions and deaths in England: a national follow-back and follow-forward record-linkage study. Lancet Public Health 2017;2:e191-201.

2. Dai X, Busby-Whitehead J, Alexander KP. Acute coronary syndrome in the older adults. J Geriatr Cardiol 2016;13:101-8.

3. Bhatnagar P, Wickramasinghe K, Wilkins E, et al. Trends in the epidemiology of cardiovascular disease in the UK. Heart 2016;102:1945-52.

4. Benjamin EJ, Muntner P, Alonso A, et al. Heart Disease and Stroke Statistics-2019 Update: A Report From the American Heart Association. Circulation 2019;139:e56-e528.

5. Odden MC, Coxson PG, Moran A, et al. The impact of the aging population on coronary heart disease in the United States. Am J Med 2011;124:827-33.e5.

6. Gurwitz JH, Col NF, Avorn J. The exclusion of the elderly and women from clinical trials in acute myocardial infarction. JAMA 1992;268:1417-22.

7. Martinez BK, White CM. Pharmacologic considerations in the management of acute coronary syndrome in elderly patients. Expert Opin Pharmacother 2019;20:1787-90.

8. Damluji AA, Forman DE, van Diepen S, et al. Older Adults in the Cardiac Intensive Care Unit: Factoring Geriatric Syndromes in the Management, Prognosis, and Process of Care: A Scientific Statement From the American Heart Association. Circulation 2020;141:e6-32.

9. Roffi M, Patrono C, Collet JP, et al. 2015 ESC Guidelines for the management of acute coronary syndromes in patients presenting without persistent ST-segment elevation: Task Force for the Management of Acute Coronary Syndromes in Patients Presenting without Persistent ST-Segment Elevation of the European Society of Cardiology (ESC). Eur Heart J 2016;37:267-315.

10. Montilla Padilla I, Martin-Asenjo R, Bueno H. Management of Acute Coronary Syndromes in Geriatric Patients. Heart Lung Circ 2017;26:107-13.

11. Sui YG, Teng SY, Qian J, et al. Gender differences in treatment strategies among patients $\geq 80$ years old with non-ST-segment elevation myocardial infarction. J Thorac Dis 2019;11:5258-65.

12. Vaccarino V, Krumholz HM, Berkman LF, et al. Sex differences in mortality after myocardial infarction. Is there evidence for an increased risk for women? Circulation 1995;91:1861-71.
13. Vicent L, Ariza-Solé A, Alegre O, et al. Octogenarian women with acute coronary syndrome present frailty and readmissions more frequently than men. Eur Heart J Acute Cardiovasc Care 2019;8:252-63.

14. Berger JS, Elliott L, Gallup D, et al. Sex differences in mortality following acute coronary syndromes. JAMA 2009;302:874-82.

15. De Carlo M, Morici N, Savonitto S, et al. Sex-Related Outcomes in Elderly Patients Presenting With Non-STSegment Elevation Acute Coronary Syndrome: Insights From the Italian Elderly ACS Study. JACC Cardiovasc Interv 2015;8:791-6.

16. Mehta LS, Beckie TM, DeVon HA, et al. Acute Myocardial Infarction in Women. Circulation 2016;133:916-47.

17. Ekerstad N, Swahn E, Janzon M, et al. Frailty is independently associated with short-term outcomes for elderly patients with non-ST-segment elevation myocardial infarction. Circulation 2011;124:2397-404.

18. Clegg A, Young J, Iliffe S, et al. Frailty in elderly people. Lancet 2013;381:752-62.

19. Díez-Villanueva P, Ariza-Sole A, Vidan MT, et al. Recommendations of the Geriatric Cardiology Section of the Spanish Society of Cardiology for the Assessment of Frailty in Elderly Patients With Heart Disease. Rev Esp Cardiol (Engl Ed) 2019;72:63-71.

20. Graham MM, Galbraith PD, O'Neill D, et al. Frailty and Outcome in Elderly Patients With Acute Coronary Syndrome. Can J Cardiol 2013;29:1610-5.

21. Rodríguez-Queraltó O, Formiga F, López-Palop R, et al. FRAIL Scale also Predicts Long-Term Outcomes in Older Patients With Acute Coronary Syndromes. J Am Med Dir Assoc 2019. [Epub ahead of print].

22. Alegre O, Formiga F, López-Palop R, et al. An Easy Assessment of Frailty at Baseline Independently Predicts Prognosis in Very Elderly Patients With Acute Coronary Syndromes. J Am Med Dir Assoc 2018;19:296-303.

23. Sanchis J, Ariza-Solé A, Abu-Assi E, et al. Invasive Versus Conservative Strategy in Frail Patients With NSTEMI: The MOSCA-FRAIL Clinical Trial Study Design. Rev Esp Cardiol (Engl Ed) 2019;72:154-9.

Cite this article as: Díez-Villanueva P, Vicent L, Alfonso F. Gender disparities in treatment response in octogenarians with acute coronary syndrome. J Thorac Dis 2020;12(4):1277-1279. doi: $10.21037 /$ jtd.2020.03.41 